\title{
LETTER TO THE EDITOR THE IMPACT OF THE ECONOMIC CRISIS ON NEONATAL HEARING SCREENING IN GREECE
}

\author{
Petros V. Vlastarakos, Efthymios Kalampalikis \\ Otolaryngology Department, MITERA Paediatric Infirmary, Athens, Greece
}

Key words: neonatal, hearing, screening, universal, deafness, otoacoustic emissions, cost-effectiveness

Address for correspondence: P. V. Vlastarakos, ENT Department, MITERA Paediatric Infirmary, 6 Erythrou Stavrou Str., 15123 Marousi-Athens, Greece. E-mail: pevlast@hotmail.com

The principal goal of TEOAE (transient-evoked otoacoustic emissions) based hearing screening programme is to identify hearing impairment present at birth in order to provide an appropriate intervention as early as possible (1). This is closely related to the importance of hearing in the development of speech and language skills, which, in turn, impacts educational, economic and social abilities. Taking into account the health burden incurred, neonatal hearing screening programmes seem to be a worthwhile investment for society as the benefits always outweigh the associated costs (2).

It has become an undisputed fact that neonatal hearing screening programmes should be universally applicable (3) and not restricted to at-risk neonates. However, the disappointing reality in Greece is that despite the efforts of Otolaryngological Societies, neonatal hearing screening programmes have not been made readily available in the maternity wards of Greek public hospitals, whereas such programmes have been successfully applied in private maternity hospitals since 1996 (4), albeit with a fee-forservice not covered by public Insurance Funds.

The recent economic crisis in Greece has resulted in a significant decline in childbirths, which reached $14.9 \%$ for the time-period between 2009 and $2012(5,6)$. The potential impact of the experienced crisis on a de facto paid service, such as a TEOAE-based hearing screening programme of a private hospital which had pioneered neonatal hearing screening nationwide, was deemed extremely important for the Paediatric Otolaryngologists who have been conducting it.

In 2009, there were 12,859 live births in the Maternity Department of our hospital, representing $10.9 \%$ of births nationwide. 6,155 babies were examined in the context of the neonatal hearing screening programme, reaching an enrollment rate of $47.86 \%$. Follow-ups $(\mathrm{n}=108)$ have not been included in the present analysis to avoid double-counting of cases. Among the screened babies, 4,214 (68.46\%) were examined in the wards, whereas 1,941 (31.54\%) were neonatal intensive care unit (NICU) graduates. The number of births in the hospital in 2012 was 7,400 representing 7.37\% of births nationwide. The total number of screened babies was 2,918 reaching an enrollment rate of $39.43 \%$. Follow-ups ( $n=106)$ were again excluded to avoid double-counting of cases. A significant decline of $8.43 \%$ in the participation to the programme was noted. $1,730(59.28 \%)$ of the newborns were examined in the wards, whereas 1,188 (40.72\%) were NICU graduates.

Hence, it appears that the observed decline in the time-period under study involved the general newborn population, as the participation rate among NICU graduates has improved, albeit not universally applied to them. Although the aforementioned decline (9.18\%) was lower than the respective decline in childbirths nationwide (14.9\%), it suggests that the experienced economic crisis negatively affects a de facto paid service, such as a privately conducted neonatal hearing screening programme, which, in turn, may bear public health consequences, whose extent cannot be fully appreciated yet.

Indeed, if we assess a tangible aspect of hearing, i.e. the rate of vocabulary growth, a typical five year-old child possesses a range of 2,000 to 10,000 words (7). In contrast, Di Carlo estimated that a typical five-year-old deaf child has approximately 25 words (8). By diving in deeper waters and examining the psychosocial health-related quality of life in children with hearing impairment who do not have access to early identification, as opposed to children with normal hearing, the two groups also seem to differ significantly (9). While it may be difficult to assign monetary value to the aforementioned aspects of deafness, there can be little doubt that there may be significant costs when children with hearing loss go un- or under-served early in life.

Despite the relatively high incidence of moderate and profound congenital sensorineural hearing loss in Central European and Western countries (5 to 7 in every 1,000 newborns) $(10,11)$, universal hearing screening programmes have not been widely applied, and most countries have only established screening programmes for high-risk infants. By contrast, metabolic diseases such as phenylketonuria, with an incidence of approximately 1 in 15,000 births, are routinely detected through newborn screening. The observed negative impact of the economic crisis on nonfinancially endorsed privately-based neonatal hearing screening programmes provides an additional incentive for incorporating neonatal hearing into the routine universal newborn screening.

Conflicts of Interest

None declared

\section{REFERENCES}

1. Aidan D, Avan P, Bonfils P. Auditory screening in neonates by means of transient evoked otoacoustic emissions: a report of 2,842 recordings. Ann Otol Rhinol Laryngol. 1999 Jun;108(6):525-31.

2. Porter HL, Neely ST, Gorga MP. Using benefit-cost ratio to select Universal Newborn Hearing Screening test criteria. Ear Hear. 2009 Aug;30(4):447-57. 
3. Rai N, Thakur N. Universal screening of newborns to detect hearing impairment - is it necessary? Int J Pediatr Otorhinolaryngol. 2013 Jun;77(6):1036-41.

4. Korres SG, Balatsouras DG, Nikolopoulos T, Korres GS, Ferekidis E. Making universal newborn hearing screening a success. Int J Pediatr Otorhinolaryngol. 2006 Feb;70(2):241-6.

5. National Statistical Service of Greece. Population dynamics in Greece in the year 2012. Press bulletin. Piraeus; 2013. (In Greek.)

6. National Statistical Service of Greece. Population dynamics in Greece in the year 2009. Press Bulletin. Piraeus; 2011. (In Greek.)

7. Nikolopoulos TP, Vlastarakos PV. Treating options for deaf children. Early Hum Dev. 2010 Nov;86(11):669-74.
8. Di Carlo LM. The deaf. New York: Prentice Hall; 1964.

9. Wake M, Hughes EK, Poulakis Z, Collins C, Rickards FW. Outcomes of children with mild-profound congenital hearing loss at 7 to 8 years: a population study. Ear Hear. 2004 Feb;25(1):1-8.

10. Davis A, Wood S. The epidemiology of childhood hearing impairment: factors relevant to planning of services. Br J Audiol. 1992 Apr;26(2):7790.

11. Kumar A, Dhanda R. The identification and management of deaf children. Indian J Pediatr. 1997 Nov-Dec;64(6):785-92.

Received September 6, 2014 Accepted in revised form December 12, 2014 